\title{
Study on the Loss of Teachers and Countermeasures of the Private University
}

\author{
Hongyan Zhao
}

\author{
Shandong Yingcai University,Jinan,250104,China \\ Keke20021003@163.com
}

Keywords: private universities; teachers' loss; Human Resources Management

\begin{abstract}
The development of private universities is facing more serious challenges with the deepening of the reform of higher education. At present, the teaching staff of private universities is facing the problem of teachers' loss. The essay analyzes the reasons of the teachers' loss from three aspects---social, organizational, personal levels, through the study on the status of teachers' loss in private universities in Shandong province. And then it puts forward some countermeasure to improve the current situation of teachers' loss in private universities.
\end{abstract}

\section{Introduction}

The private higher education was founded in the nineteen eighties. At present, it has made achievements attracting worldwide attention in universities size, universities level and teaching conditions. Private higher education is developing rapidly and getting considerable development since 21st Century. It has become an important part of the development of China's higher education, and made a positive contribution in the training implementation plan of our country. However, the large loss of teachers and poor stability has restricted the healthy and sustainable development of private universities seriously. Therefore, building a high-quality and stable teachers team is the important and urgent problem to study and solve in present private universities.

\section{Analysis of the current situation about the loss of private colleges' teachers in Shandong Province}

Serious loss of teachers is a stern problem for private colleges. Because private colleges started relatively late, it is not perfect in all directions. Runaway phenomenon of loss of teachers in private colleges has appeared in many places---a large number of outstanding teachers have lost. According to statistics, $85 \%$ teachers in the loss of the private universities in Shandong province have left voluntarily. Among them, postgraduate degree or above accounted for $70 \%$, intermediate titles accounted for more than $80 \%$.

Survey of a private university established in 2000 in our province has proved that the average annual rate is about $12 \%$ in loss of teachers so far, and most of whom are rich teaching experience and high quality excellent teachers. These former teachers have worked in universities for different time, some leaving after a year or two or three years or more than 5 years. These teachers have gone to three directions on the whole: part to full-time graduate or Dr., part to the relevant industries with better development prospect and part admitting to public servants or business units. This phenomenon not only brought adverse effects to universities' normal teaching work but also increased cost of human resources management.

\section{Analysis of the causes of high loss rate of teachers in private universities}

Social level.Although China's "Private Education Promotion Law" clearly provides private and public universities teachers have the equal legal status; private universities' teaching staff should enjoy the same rights by law with public universities teachers in vocational training, employment, teaching age and length of service calculation, commendation reward, social activities and so on. 
But in fact, low social identity of private college degree result in the rights of the private college teachers can not get effective guarantee, and even many legal rights will be violated. That our society lacks awareness about the nature, role and status of private universities leads to identity discrimination for these teachers.

College level.(1)Recruitment policy.Universities teachers' recruitment tries to ensure to introduce high quality talents, but in the recruitment system, there are still some problems affecting the introduction of teacher quality, which are mainly in the following several points: one is the incomplete evaluation. At their early stage, because of the shortage of teachers, universities were eager to increase teachers, but high degree talents were in a seller's market, so recruitment examinations for teachers are incomplete. Two is relatively strong teacher appointment system randomness and disorder. At present, numbers of private universities tend to be based on the heads' individual decision, and some universities share with relatives and friends, lacking strict norms of operation to bring a great negative impact on the in-service teachers in psychology. The imperfect procedure remains hidden dangers for high loss rate.

(2)Performance appraisal.In private universities, full-time teachers have larger workload and their workload is mainly in teaching. But scientific research level is its weakness, and many subjects lack backbone teachers and high level discipline leaders. In quantitative assessment of teachers' teaching work, many appraisals also have many deficiencies, mainly reflected in lacking objective and scientific index system to evaluate teaching effect. At present, private universities evaluation index includes three kinds: one is student evaluating teaching, and this index is influenced by students' subjective effects so its accuracy is not high. Two is supervisors evaluating teaching, and in the index assessment, subjects do not know the real teaching situation but just in a matter of routine, so it is neither objective nor unfair. Three is teachers evaluating each other, and considering colleague relationship they tend to give good evaluations. The series of problems in performance appraisal do not enable to encourage teachers to work hard rather than causing teachers psychologically unfair.

(3)Salary system.Compared with public universities, for private universities teachers, it is far from both in salary, bonus, scientific research, or in social planning and other social welfare, and this is very important facts considering leaving or staying for teachers. On the wage level, private colleges and universities teachers' salaries are generally lower than the basic wage level of public teachers, and the weekly class capacity is quite large. What' s more, there is a housing problem, because most money comes from student tuition fees for private colleges, and being in its newly established or developing stage, the capital is basically used in more urgent teaching and dormitory building, housing problem of teachers can not be solved.

(4)Training and development mechanism.Many private universities lack long-term planning for the construction of teaching staff, so the phenomenon "heavy use, light training" is relatively common. To reduce costs and reduce expenditure, universities tend to limit teachers to participate in social activities and not to support the necessary academic exchanges, academic research, teaching practice etc. These lead to too little scientific research and not strong academic atmosphere, bounding teachers' enthusiasm, initiative and creativity, so teachers feel self improvement and occupation career development space is limited, so enlarging the loss of teachers.

Individual level.From teachers' own perspective, on the one hand, private college students have poor foundation and with little interest in learning, so some teachers are not satisfied with the private college Humanities and scientific research atmosphere, their pay is not met satisfying results, no sense of achievement or work enthusiasm, then they choose to flow again to meet their own work achievement demand; on the other hand, in the current social competition pressure, just graduates graduating from university lack advantages, so to select private Universities as a springboard. When having accumulated certain experience, been familiar with and mastered the skill and ability, promoted to a certain level of titles, many teachers choose to switch to public higher education. Because universities only put on teaching, but lack of scientific training, objectively suppresses teachers' occupation development, this increases the flow of teachers. 


\section{Countermeasures and suggestions for improving the status of loss of private college and universities teachers}

Respect social status of teachers of private universities, improve the social security system.In addition to "Private Education Promotion Law", the provincial people's government should formulate corresponding implementation details as soon as possible, to ensure that the private universities can be in accordance with the relevant provisions, safeguard their legitimate rights and interests to be implemented. In addition, departments of government and education should help the private universities to establish Party Organizations and Trade Unions, to establish the staff representative assembly system to safeguard the interests of universities and teachers. At the same time relative departments should set the teachers qualification system and social security system, as long as teachers have teachers qualification, whether in the public universities or in private colleges, they should enjoy the same social security law, enjoy the same treatment especially in social planning, housing provident fund, welfare, insurance. If private universities are indeed difficult, government and education administrative departments should be subsidized and assist in solving.

Improve the internal management system, eliminate teachers discontent.In teachers appointment, private universities should make "open recruitment, equal competition, a comprehensive study, select" recruitment policy to ensure the democratic, scientific decision-making, reducing use of randomness, continuously improving the efficiency of personnel decision-making, guarantee the quality of teachers; In the performance appraisal, performance appraisal index is extended to five for teachers: teaching workload,scientific research,evaluation of teaching quality assessment,assessment,high level service competition. Based on the comprehensive assessment of teachers, providing teachers with the feedback makes its weakness, improves performance and improves the ability and quality; at the same time, evaluation results can be used as important basis of teachers' promotion, rewards and punishment, training. In addition, universities also can set up a suggestion box or an opinion box, or a director mailbox in the universities website, to let the teacher speak out their own ideas. Once teaching effect and quality decline or discontent rising problems appear, universities must be communicate with the teacher to solve problems timely; In the salary system, private universities should increase teacher pay gap according to the job, performance and contribution to arouse the enthusiasm of the teachers. At the same time, hey should enhance private colleges appeal to outstanding top-notch talents, and reduce the disorderly flow of teachers through effective ways of cultural motivation, goal motivation, emotional motivation, occupation development motivation.

Establish a correct outlook on life and career concept, stabilize teaching team.Private universities should improve the private college teachers understanding of the position and role of private colleges through strengthening teacher occupation moral and legal education, and further clarify private universities play an important role in social politics, economy, culture, education and other fields. Compared with public universities, private colleges just have different investment main body, so teaching in private universities have the same position, meaning and value with public universities. Then universities can establish the values of teachers and career concept, with true love and dedication. At the same time, strengthening the ideological and moral construction of teachers make them realize the glorious mission of our position, responsibility and historical responsibility, treat and understand correctly teachers position and responsibility, change employment thought as the master consciousness, which plays an important role in stabilizing the teaching staff.

\section{Conclusion}

This paper analyzes analysis reasons of high teachers' loss in private college through research on status of the loss of teachers in private universities in Shandong province from three aspects of social, organizational, personal, and puts forward several suggestions to improve the status. Based on the measures of improving the status, this paper puts forward corresponding countermeasures from three aspects, but specific operation method is yet to be further exploration and study. The construction of stability of teaching team for private universities in Shandong province also needs 
the combination of theoretical and empirical research, and also constantly sum up experience in development practice to improve the theory.

\section{Acknowledgements}

This work was financially supported by Shandong province occupation education and adult education research five-year plan project(2011ZCJGM10)

\section{Reference}

[1] Zhou Jingjuan. WL Institute drain problem analysis and countermeasure research of [D]. Dalian: Master's degree thesis of Dalian University of Technology, 2004

[2] Liu Rong on loss causes and Countermeasures --take the private universities for reasons of loss of teachers and Countermeasures [J]. review employees, 2010

[3] Ni Juanzhi, Shen Tianwei, Yao Peng. The private college teaching staff construction situation and construction strategy research -- from the organizational commitment of teachers in private colleges loss at [J]. social science, 2010.8.

[4]Gary Dessler Human Resource Management [M] Pearson Education, 2009.

[5]Hu Lifang analysis about enterprise brain drain reason and Countermeasure of [J]. Market Weekly ,2010,(4):26-29.

[6]Wang Jirong. Analysis of the phenomenon of [J]. Journal of Beijing University of Posts and Telecommunications staff turnover of private enterprises, 2011,(6):15-18.

[7]Dang Wenqing. The flow of talent situation and influence factors analysis [J],Population Journal, 2011,(7):34-36. 